\title{
Mental and physical comorbidity in an Arab primary health care setting
}

\author{
Sulaiman Alkhadhari ${ }^{1,4^{*}}$ D, Aseel Omran Alsabrrie ${ }^{2}$, Jude Uzoma Ohaeri ${ }^{1}$, Ramani Varghese ${ }^{1}$, \\ Muhammad Ajmal Zahid ${ }^{1}$ and Benoit $\mathrm{H} \mathrm{Mulsant}^{3}$
}

\begin{abstract}
Background: There are no published studies on the comorbidity of common mental conditions (anxiety, depression, and somatization) and physical illnesses in the Arab world. Our aim was to estimate the prevalence of common mental conditions comorbid with physical illnesses among primary care attenders in Kuwait, and the sociodemographic characteristics associated with this comorbidity.
\end{abstract}

Methods: The Patient Health Questionnaires for somatization, anxiety and depression (PHQ-SAD) were administered to a representative sample of 1046 attenders (M: $F=429: 617$; mean age 37.6, SD 12.7) seen in primary care clinics in Kuwait. Based on well-established cut-off scores, the presence and severity of three mental conditions -depression, anxiety, and somatization - was ascertained; physical diagnoses were ascertained by the attending physicians.

Results: Of 1046 respondents, 442 (42.3\%) had at least one mental condition and 670 (64.1\%) had a physical illness diagnosis, viz: diabetes mellitus $(248 / 670=37.0 \%)$, hypertension $(229 / 670=34.2 \%)$, asthma $(82 / 670=12.2 \%)$, nonchronic physical illnesses $(63 / 670=9.4 \%)$, or heart disease $(48 / 670=7.2 \%)$, with $34.4 \%(360 / 1046)$ having mentalphysical comorbidity. Male: female ratio for the 670 subjects was 287: 383. The unadjusted odds ratio (OR) for having a mental condition in those with a physical illness vs. those without a physical illness was $4.16(95 \%$ C.I. $=3.12,5.55)$. Comorbidity was associated with older age, being divorced or widowed, a lower level of education, and poorer living conditions. Regardless of the physical illness, the most frequent comorbid mental disorder was somatization. The prevalence and severity of mental conditions were associated with the number of physical illnesses.

Conclusion: As has been reported in other parts of the world, somatization, anxiety, and depression are highly prevalent among primary care attenders in Kuwait and they are typically comorbid with physical illness. Strategies for their prevention and treatment need to take into consideration their association with physical illness and social disadvantage.

Keywords: Primary care attenders, Mental health, Depression, Anxiety, Physical illness, Prevalence, Comorbidity

\section{Background}

The literature has consistently shown that anxiety, depression, and somatization are highly prevalent among primary care attenders. The estimated prevalence rates in recent large international studies are: $31-35.8 \%$ for depression, $19-25.6 \%$ for anxiety, and $18-28.8 \%$ for somatoform disorders $[1,2]$. The studies indicated that these are the commonest mental disorders presenting in primary care settings.

\footnotetext{
* Correspondence: alkhadhari@hsc.edu.kw; Alkhadhari@gmail.com 'Department of Psychiatry, Faculty of Medicine, Safat, Kuwait

${ }^{4}$ Department of Psychiatry, Faculty of Medicine, Health Sciences Center, PO Box 24923, 13110 Safat, Kuwait

Full list of author information is available at the end of the article
}

This high prevalence has been attributed in large part to their co-occurrence with the physical illnesses that are known to be commonly prevalent in primary care settings, such as diabetes mellitus, hypertension, heart diseases and asthma [3]. The issues surrounding comorbidity of mental and physical disorders have been of international concern, being the subject of a book review by WHO consultants [3]. A major concern is that the successes of medicine prolong life for subjects with these physical illnesses, thus adding years at risk for mental comorbidity [3]. The pathways linking comorbid mental and physical conditions are complex and bidirectional, such that, a physical disorder may cause a mental one, a mental disorder may place a person at risk for a physical

(c) The Author(s). 2018 Open Access This article is distributed under the terms of the Creative Commons Attribution 4.0 International License (http://creativecommons.org/licenses/by/4.0/), which permits unrestricted use, distribution, and reproduction in any medium, provided you give appropriate credit to the original author(s) and the source, provide a link to the Creative Commons license, and indicate if changes were made. The Creative Commons Public Domain Dedication waiver (http://creativecommons.org/publicdomain/zero/1.0/) applies to the data made available in this article, unless otherwise stated. 
one, and some mental and physical disorders share risk factors, such as chronic stressful social life situations, physical inactivity, overweight, smoking, substance use disorders and endocrine dysregulation [3]. Regardless of the chronological order in which they occur, or the causal pathways linking them, the comorbidity of a mental and physical condition may impact the mode of presentation, clinical severity, response to treatment, and burden of illness of both conditions [1-4]. Despite the robustness of these findings and the availability of effective interventions that integrate the care of common mental and physical conditions [5], many physicians in the Arab world pay scant attention to comorbidity issues [6-8], where the high prevalence and co-occurrence of anxiety and depression has been reported in both general population samples $[9,10]$ and primary care settings $[7,8]$. However, to our knowledge, there are no published studies of the comorbidity of these common mental conditions and physical illnesses in the Arab world.

\section{Objectives}

Thus we conducted a study in a representative sample of Kuwaiti primary care attenders, the objectives of which were: to assess the comorbidity of depression, anxiety, and somatization with common chronic physical illnesses - diabetes mellitus, hypertension, heart disease, and asthma, as well as non-chronic medical conditions; and to explore the patients' characteristics associated with this comorbidity.

\section{Methods}

The methods for sampling and assessing participants have been described in detail elsewhere [6] and are briefly summarized below.

\section{Sampling}

After the ethics approval for the study was obtained from the Scientific and Research Committee, Ministry of Health, Kuwait, 16 of 87 primary health centers in Kuwait were randomly selected. A sample size of 1000 participants was estimated to provide a precision of $2 \%$, given the estimated $16 \%$ prevalence of psychiatric disorders among PHC attenders in routine consultation, and a significance level set at 0.05 . Thus, 1046 participants were recruited to allow for up to $5 \%$ cases with missing data. Participants gave written informed consent.

\section{Physical diagnoses}

Physical diagnoses were ascertained by the primary care physicians based on the International Classification of Diseases, 10th edition (ICD-10) [11]. When necessary, these diagnoses were confirmed by further investigations, (such as radiological and electro-encephalograhic) or hospital-based consultants.

\section{Psychopathology instruments}

The Patient Health Questionnaire-Somatic/Anxiety/Depression (PHQ-SAD) is an easy-to administer brief assessment tool, designed to measure probable rates of psychiatric morbidity in the primary care settings, based on the DSM-IV [12]. The PHQ-SAD has been widely used to assess the presence and severity of depression, anxiety, or somatization and it has been reported to have good psychometric properties [13-16]. It comprises three questionnaires: the Patient Health Questionnare-9 (PHQ-9); the Generalized Anxiety Disorder-7 (GAD-7), and the Patient Health Questionnaire-15 Somatic Symptoms (PHQ-15).

The PHQ-9 is a self-administered 9-item questionnaire used to assess for the presence of depressive symptoms. The 4-option response format allows scores of $0,1,2$ and 3 corresponding to "not at all", "several days", "more than half the days", and "nearly every day", respectively. The total score ranges from 0 to 27, with scores of 5,10 , 15 , and 20 representing cut points for mild, moderate, moderately severe, and severe depression, respectively [12]. The PHQ-9 has been validated and extensively used in medical populations, with high sensitivity and specificity both for case detection and diagnosis of depressive disorders. Similarly, the GAD-7 is a self-administered 7-item questionnaire used to assess for the presence of generalized anxiety disorder symptoms. Using the same 4-option responses as the PHQ-9, the total score ranges from 0 to 21 , with scores of 5,10 , and 15 representing cut points for mild, moderate and severe anxiety, respectively. The GAD-7 has been validated and extensively used in primary care settings with good sensitivity and specificity to screen for generalized anxiety disorder. Finally, the PHQ-15 is a self-administered 15-item questionnaire used to assess for the presence of symptoms of somatoform disorders in primary care settings. The 3-option response format allows scores of 0 , 1 , and 2, corresponding to "not at all", "bothered a little", and "bothered a lot". The total score ranges from 0 to 30 , with scores of 5,10 , and 15 representing cut points for somatic symptoms of low, medium, and high severity, respectively.

\section{Procedures}

On alternative days during a 5-month period (May 1st to September 30th, 2012), the PHQ-SAD was administered to all the consenting patients seen in the selected primary care clinics, while they waited to be seen by their physicians. The Arabic or the English versions were used as appropriate. Illiterate patients were assisted in completing the questionnaires. Primary care physicians were advised to refer to consulting psychiatrists, all patients who screened positive for a mental disorder. 


\section{Data analyses}

The data were analyzed on SSPS, version 22 (IBM corp. Armonk, NY: 2013). Descriptive statistics, including mean, $\mathrm{SD}$, frequencies, and percentages were used to describe the data. Following recommendations in the literature, a cut - off score of 10 or above was used to ascertain the probable prevalence rates of all three mental conditions [13-15]. Thus, somatization, anxiety, and depression total scores were coded as $>/=10$ (=1, i.e., clinical depression/ anxiety/ somatization is present) or $<10(=0$, i.e., no clinical depression/ anxiety/ somatization), and used as grouping variables for chi-square tests with gender, age group, nationality, marital status, and level of education. Similarly, the four physical illnesses were used in chi-square tests with socio-demographic characteristics and mental conditions. To evaluate the impact of multiple physical illnesses, we used one-way ANOVA to assess the association between psychopathology scores and number of physical illnesses. Odds ratio was used for comparing the odds of having a comorbid physical and mental health condition vs. only a physical condition. For all tests, a $p$ - value of 0.05 was used to determine statistical significance.

\section{Results}

\section{Characteristics of the overall sample}

Of 1046 participants, aged 18-80 years (mean 37.6, SD 12.7 ), consisting of 429 males (aged 39.2, SD 12.6), and 617 females (aged 36.5, SD 12.6; $t=3.4, \mathrm{df}=1044, P<$ 0.001), 764 (73\%) were married, 801 (77\%) were Kuwaiti nationals, and 337 (32\%) had a University degree.

\section{Characteristics of the participants with a physical illness}

Of the 1046 respondents, 670 (64.1\%) had a diagnosis of a physical illness for which at least one medication was prescribed; 383 of them (57.2\%) were females, while
287(42.8\%) were males; 512 (76.4\%) were married; 300 (44.8\%) had a College or University degree; and 608 (90.7\%) reported their socio-economic status as medium or high (Table 1). Physical illnesses $(N=670)$ included diabetes mellitus (37.0\%), hypertension (34.2\%), asthma (12.2\%), other non-chronic physical illness, such as upper respiratory tract infections or diarrhea $(9.4 \%)$, and heart disease (7.2\%). The mean (SD) age was significantly older in participants with a heart disease (52.7, $\mathrm{SD}=13.8$ years), hypertension (49.9, $\mathrm{SD}=12.6)$, or diabetes mellitus $(49.0, \mathrm{SD}=13.3)$, than in those with non-chronic illnesses $(37.4, \mathrm{SD}=$ 11.3 years) or asthma (35.9, $\mathrm{SD}=10.5)$ (all $p$ 's $<0.001$ ).

Of the 1046 participants, 376 (35.9\%; i.e., 376/1046) had no diagnosed physical illness, 275 (26.3\%) had one, 148 (14.1\%) had two, and 33 (3.2\%) had 3 or more. In addition to these 456 participants with one or more chronic physical illnesses, 63 had minor non-chronic conditions, and there was insufficient information to categorize the number of comorbid physical illnesses in 151 participants. The number of chronic physical illnesses was not associated with gender, but it was significantly associated with older age $\left(x^{2}=331, \mathrm{df}=\right.$ 9, $p<0.0001)$. Participants who were divorced or widowed were also significantly more likely to have more physical conditions than those who were either single or married $\left(x^{2}=\right.$ $159.5, \mathrm{df}=9, p<0.0001)$; participants with less than 12 years of education were significantly more likely to have multiple physical illnesses, than those with higher levels of education $\left(X^{2}=152.6, \mathrm{df}=12, p<0.001\right)$; and participants with poorer living conditions were significantly more likely to have multiple physical illnesses than those who reported better living conditions $\left(\mathrm{X}^{2}=21.2, \mathrm{df}=6, p<0.002\right)$.

\section{Mental - physical comorbidity}

Of 1046 participants, 360 (34.4\%) had both at least one mental condition and at least one diagnosed physical

Table 1 Socio-demographic characteristics of participants with physical illnesses ( $N=670)$

\begin{tabular}{|c|c|c|c|c|c|c|c|c|c|c|c|c|c|}
\hline \multirow[t]{3}{*}{ Disease } & \multicolumn{3}{|c|}{ Living condition } & \multicolumn{3}{|c|}{ Level of education } & \multicolumn{4}{|c|}{ Marital status } & \multicolumn{2}{|c|}{ Gender } & \multirow{3}{*}{$\begin{array}{l}\text { Age } \\
\text { Mear } \\
\text { (SD) }\end{array}$} \\
\hline & \multicolumn{3}{|l|}{$\mathrm{n}(\%)^{\mathrm{b}}$} & \multicolumn{3}{|l|}{$\mathrm{n}(\%)$} & \multicolumn{4}{|l|}{$\mathrm{n}(\%)$} & \multicolumn{2}{|l|}{$\bar{n}(\%)$} & \\
\hline & Low & Medium & High & $\begin{array}{l}\text { Illiterate/ } \\
\text { Primary }\end{array}$ & High school & $\begin{array}{l}\text { College/ } \\
\text { University }\end{array}$ & Single & Married & Divor-ced & Widow & Male & Female & \\
\hline $\begin{array}{l}\text { Diabetes } \\
(N=248)\end{array}$ & $\begin{array}{l}28 \\
(11.3)\end{array}$ & $\begin{array}{l}171 \\
(69.0)\end{array}$ & $\begin{array}{l}48 \\
(19.8)\end{array}$ & $\begin{array}{l}98 \\
(39.5)\end{array}$ & $\begin{array}{l}55 \\
(22.2)\end{array}$ & $\begin{array}{l}95 \\
(38.3)\end{array}$ & $\begin{array}{l}16 \\
(6.5)\end{array}$ & $\begin{array}{l}193 \\
(77.9)\end{array}$ & $\begin{array}{l}7 \\
(2.8)\end{array}$ & $\begin{array}{l}32 \\
(12.9)\end{array}$ & $\begin{array}{l}120 \\
(48.4)\end{array}$ & $\begin{array}{l}128 \\
(51.6)\end{array}$ & $\begin{array}{l}49 \\
(13)\end{array}$ \\
\hline $\begin{array}{l}\text { Hypertension } \\
(N=229)\end{array}$ & $\begin{array}{l}29 \\
(12.7)\end{array}$ & $\begin{array}{l}157 \\
(68.6)\end{array}$ & $\begin{array}{l}43 \\
(18.8)\end{array}$ & $\begin{array}{l}86 \\
(37.5)\end{array}$ & $\begin{array}{l}49 \\
(21.4)\end{array}$ & $\begin{array}{l}94 \\
(42.1)\end{array}$ & $\begin{array}{l}14 \\
(6.1)\end{array}$ & $\begin{array}{l}177 \\
(77.3)\end{array}$ & $\begin{array}{l}6 \\
(2.6)\end{array}$ & $\begin{array}{l}32 \\
(14.0)\end{array}$ & $\begin{array}{l}103 \\
(45.0)\end{array}$ & $\begin{array}{l}126 \\
(55.0)\end{array}$ & $\begin{array}{l}49.9 \\
(12)\end{array}$ \\
\hline $\begin{array}{l}\text { Others }^{a} \\
(N=63)\end{array}$ & $\begin{array}{l}5 \\
(7.9)\end{array}$ & $\begin{array}{l}45 \\
(71.4)\end{array}$ & $\begin{array}{l}13 \\
(20.6)\end{array}$ & $\begin{array}{l}9 \\
(14.2)\end{array}$ & $\begin{array}{l}13 \\
(20.6)\end{array}$ & $\begin{array}{l}41 \\
(65.1)\end{array}$ & $\begin{array}{l}11 \\
(17.5)\end{array}$ & $\begin{array}{l}46 \\
(73.0)\end{array}$ & $\begin{array}{l}6 \\
(9.5)\end{array}$ & - & $\begin{array}{l}15 \\
(23.8)\end{array}$ & $\begin{array}{l}48 \\
(76.2)\end{array}$ & $\begin{array}{c}37.4 \\
(11)\end{array}$ \\
\hline $\begin{array}{l}\text { Heart disease } \\
(N=48)\end{array}$ & $\begin{array}{l}1 \\
(2.1)\end{array}$ & $\begin{array}{l}33 \\
(68.8)\end{array}$ & $\begin{array}{l}14 \\
(29.2)\end{array}$ & $\begin{array}{l}22 \\
(45.8)\end{array}$ & $\begin{array}{l}9 \\
(18.8)\end{array}$ & $\begin{array}{l}17 \\
(35.4)\end{array}$ & $\begin{array}{l}3 \\
(6.3)\end{array}$ & $\begin{array}{l}36 \\
(75.0)\end{array}$ & $\begin{array}{l}1 \\
(2.1)\end{array}$ & $\begin{array}{l}8 \\
(16.7)\end{array}$ & $\begin{array}{l}24 \\
(50.0)\end{array}$ & $\begin{array}{l}24 \\
(50.0)\end{array}$ & $\begin{array}{l}52.7 \\
(13)\end{array}$ \\
\hline $\begin{array}{l}\text { Asthma } \\
(N=82)\end{array}$ & $\begin{array}{l}6 \\
(7.3)\end{array}$ & $\begin{array}{l}59 \\
(72.0)\end{array}$ & $\begin{array}{l}17 \\
(20.7)\end{array}$ & $\begin{array}{l}11 \\
(13.4)\end{array}$ & $\begin{array}{l}18 \\
(22.0)\end{array}$ & $\begin{array}{l}53 \\
(64.7)\end{array}$ & $\begin{array}{l}14 \\
(17.1)\end{array}$ & $\begin{array}{l}60 \\
(73.2)\end{array}$ & $\begin{array}{l}6 \\
(7.3)\end{array}$ & $\begin{array}{l}2 \\
(2.4)\end{array}$ & $\begin{array}{l}25 \\
(30.5)\end{array}$ & $\begin{array}{l}57 \\
(69.5)\end{array}$ & $\begin{array}{l}35.9 \\
(10)\end{array}$ \\
\hline
\end{tabular}

*Other: non-chronic mild conditions, e.g., upper respiratory tract infection, etc

b In Kuwait, an affluent country, a total monthly family income for Kuwaiti nationals of <KD 800 (about US\$2600), is regarded as low living condition; medium living condition is <KD 2000 (i.e., US\$6600); and high living condition is > KD 2000 
illness. Hence, the prevalence of a comorbid mental condition was 53.7\% (360/670) among those with at least one physical diagnosis, compared to a prevalence of $21.8 \%(82 / 376)$ of at least one mental disorder among those without a diagnosed physical illness. The unadjusted odds ratio (OR) for having a mental condition in those with a physical illness vs. those without a physical illness was 4.16 (95\% C.I. $=3.12,5.55)$.

Table 2 sought to assess (by chi-square) the association of mental conditions (and their possible combinations) with specific physical illnesses, with a view to seeing whether particular mental conditions occurred more frequently in specific physical conditions. The most common mental condition comorbid with physical illnesses was somatization (17.9-20.8\%) or the co-occurrence of all three mental conditions (13.7-28.6\%). These associations were statistically significant for hypertension, asthma and non-chronic medical conditions..

The psychopathology scores (i.e., PHQ-9, GAD-7 and PHQ-15 scores) were significantly associated with higher number of physical illnesses $(p<0.0001)$ (see Table 3 ). Furthermore, as shown in Table 3, although participants with heart diseases or asthma had higher psychopathology scores than participants with diabetes mellitus or hypertension, the differences were statistically significant only for asthma (vs. diabetes and hypertension) and for somatization or depression scores.

\section{Discussion}

Using a validated instrument, we assessed the relationship between common mental conditions and comorbid physical illness in a representative sample of Kuwaiti primary care attenders. To our knowledge, this is the first study to assess the prevalence of comorbid mental and physical illness in the Arab World. While depression and anxiety have consistently shown to be more prevalent among women [6], we did not find that comorbid mental and physical disorders were associated with gender. However, they were associated with older age, lower level of education, being divorced or widowhood, and poorer living condition. The association with older age is congruent with the low prevalence of chronic physical illness in younger people [17]. The association with social disadvantage suggests that preventative or therapeutic interventions targeting these social determinants of health could be beneficial and ultimately reduce health care costs [18].

The odds of having a mental condition were more than four-fold higher in those with a physical illness than in those without one. This finding is also congruent with the literature $[4,19-21]$. Both the prevalence and the severity of mental conditions increased with the number of comorbid physical illnesses. This "dose-response" relationship identifies a group of primary care attenders at high risk for comorbid mental conditions who could also be the target of specific preventative or therapeutic interventions.

The most common comorbid mental condition in those with a physical illness was somatization, either alone or combined with depression and anxiety. However, there was no robust association between specific mental and physical illnesses. Again, this is congruent with the literature [22]. Despite this lack of specificity, comorbid mental and physical disorders result in poorer prognosis, increased resource utilization, higher health care costs, functional disability, and poorer treatment compliance $[4,21,23]$.

The implication of this endorsement of comorbidity as the norm in clinical presentation [24] is that the transdiagnostic approach should be applied in the understanding and treatment of comorbid conditions [25]. This means searching for and treating common underlying phenomena that maintain co-occurring medical conditions, the effective amelioration of which should significantly reduce morbidity [26].

Table 2 Association of physical and mental conditions

\begin{tabular}{|c|c|c|c|c|c|}
\hline & Diabetes $(N=248)$ & Hypertension $(\mathrm{N}=229)$ & Others $(N=63)$ & Heart Disease $(\mathrm{N}=48)$ & Asthma $(\mathrm{N}=82)$ \\
\hline No Mental Disorder $(n, \%)$ & $134(54.0)$ & $110(48.0)$ & $20(31.7)$ & $19(39.6)$ & $27(32.9)$ \\
\hline Somatization (n, \%) & $34(13.7)$ & $41(17.9)$ & $11(17.5)$ & $10(20.8)$ & $15(18.3)$ \\
\hline Anxiety (n, \%) & $3(1.2)$ & $4(1.8)$ & $2(3.26)$ & 0 & $2(2.4)$ \\
\hline Depression (n, \%) & $12(4.8)$ & $6(2.6)$ & $2(3.2)$ & $1(2.1)$ & $2(2.4)$ \\
\hline Somatization + Anxiety (n, \%) & $10(4.0)$ & $12(5.2)$ & $1(1.6)$ & $3(6.3)$ & $3(3.7)$ \\
\hline Anxiety + Depression $(n, \%)$ & $6(2.4)$ & $7(3.1)$ & $1(1.6)$ & $2(4.2)$ & $2(2.4)$ \\
\hline Somatization + Depression $(\mathrm{n}, \%)$ & $15(6.0)$ & $16(7.0)$ & $8(12.7)$ & $3(6.3)$ & $13(15.9)$ \\
\hline All 3 mental disorders ( $n, \%)$ & $34(13.7)$ & $33(14.4)$ & $18(28.6)$ & $10(20.8)$ & $18(22)$ \\
\hline Statistics & $x^{2}=6.45$ & $x^{2}=20.7$ & $x^{2}=37.9$ & $x^{2}=13.4$ & $x^{2}=41.3$ \\
\hline$d f$ & $d f=7$ & $d f=7$ & $d f=7$ & $d f=7$ & $d f=7$ \\
\hline$p$ value & $p>0.05$ & $p<0.004$ & $p<0.0001$ & $p=0.063$ & $p=0.0001$ \\
\hline
\end{tabular}


Table 3 Severity of psychopathology vs. number and types of physical illnesses

\begin{tabular}{|c|c|c|c|}
\hline \multirow[t]{2}{*}{ Number of physical illnesses ${ }^{a}$} & PHQ-15: Somatization & GAD-7: Anxiety & PHQ-9: Depression \\
\hline & Mean (SD) & Mean (SD) & Mean (SD) \\
\hline No physical illness $(n=376)$ & $6.8(4.7)$ & $4.6(4.5)$ & $5.6(4.9)$ \\
\hline One physical illness $(n=275)$ & $8.5(5.9)$ & $5.9(5.3)$ & $6.8(6.2)$ \\
\hline Two physical illnesses $(n=148)$ & $9.6(6.3)$ & $6.9(6.2)$ & $8.1(6.9)$ \\
\hline Three or more physical illnesses $(n=33)$ & $11.1(6.2)$ & $8.6(7.7)$ & $8.7(6.5)$ \\
\hline Statistics, $p$ value & $F_{3,828}=18.9, p<0.001$ & $F_{3,828}=13.9, p<0.001$ & $F_{3,828}=10.8, p<0.001$ \\
\hline Multiple comparisons & $\begin{array}{l}3 \text { \& } 2 \text { illnesses }>1 \text { and } \\
\text { no illness }\end{array}$ & $\begin{array}{l}3 \& 2 \text { illnesses }>1 \text { and } \\
\text { no illness }\end{array}$ & $\begin{array}{l}3,2 \text {, and } 1 \text { illnesses }> \\
\text { no illness }\end{array}$ \\
\hline \multicolumn{4}{|l|}{ Specific physical illness } \\
\hline Diabetes mellitus ( $n=248$ ) & $8.3(5.9)$ & $6.3(6.0)$ & $7.0(6.6)$ \\
\hline Hypertension $(n=229)$ & $8.9(5.9)$ & $6.5(6.3)$ & $7.4(6.6)$ \\
\hline Heart disease $(n=48)$ & $10.0(6.4)$ & $7.5(7.1)$ & $8.2(6.8)$ \\
\hline Asthma $(n=82)$ & $11.8(6.6)$ & $7.3(5.2)$ & $8.9(6.2)$ \\
\hline$p$ value & $\begin{array}{l}F_{3,603}=7.4 ; p<0.01 \text { for asthma } \\
\text { vs. diabetes and hypertension }\end{array}$ & $P>0.05$ & $\begin{array}{l}F=1.9 ; p>0.05 \text {. But for asthma } \\
\text { vs. diabetes: } t=2.4, p<0.02\end{array}$ \\
\hline
\end{tabular}

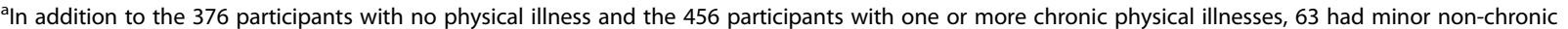
conditions, and there was insufficient information to categorize the number of physical illnesses in 151 participants

The strengths of this study include the use of a validated instrument in a representative sample. Its limitations include its cross-sectional design and the narrow range of chronic physical illnesses identified in our sample. This narrow range of illnesses seen in a primary care sample is reflective of the health care system in a small affluent country, where patients have easy and direct access to highly specialized hospitals for treating many chronic illnesses such as cancer, neurological, renal, or skin diseases (i.e., these specialist hospitals also offer easy access in walk-in clinics without the need of a referral from primary care physicians). Despite these limitations, our findings are congruent with the literature and support the call for primary care physicians to be mindful of the psychological and social contexts of patients who present primarily with physical illness, particularly if these patients have multiple medical illnesses or are disadvantaged socially.

\section{Conclusion}

Somatization, anxiety, and depression are highly prevalent among primary care attenders in Kuwait, as has been widely reported in the literature, and they are typically comorbid with physical illness. Strategies for their prevention and treatment need to take into consideration their association with physical illness and social disadvantage.

\section{Abbreviations}

ANOVA: Analysis of Variance; Cl: Confidence Interval; DSM IV: Diagnostic and Statistical Manual of Mental Disorders 4th Edition; GAD-7: General Anxiety disorder is 7 item questionnaires; PHQ-15: Patient Health Questionnaires is 15 item questionnaires; PHQ-9: Patient Health Questionnaires is 9 item questionnaires; PHQ-SAD: Patient Health Questionnaires for somatization/ anxiety/depression; SD: Standard Deviation; SPSS: Statistical Package for Social Science

\section{Funding}

The study was financed by the authors.

\section{Availability of data and materials}

The datasets used and analysed during the current study are available from the corresponding author on reasonable request.

\section{Authors' contributions}

SA, AOA and MAZ conceived, planned and executed the project. RV collated the data. JUO and BMH, SA and MAZ analyzed the data and drafted the manuscript. All authors read and approved the manuscript.

\section{Ethics approval and consent to participate}

The study was approved by the Research and Ethical Committee of the Ministry of Health, Kuwait. Participants gave written informed consent.

\section{Consent for publication}

Not applicable.

\section{Competing interests}

The authors declare that they have no competing interests.

\section{Publisher's Note}

Springer Nature remains neutral with regard to jurisdictional claims in published maps and institutional affiliations.

\section{Author details}

'Department of Psychiatry, Faculty of Medicine, Safat, Kuwait. ${ }^{2}$ Abdullah \& Shereefa Almehry Health Center (Alkhaldiya Polyclinic), Kuwait City, Kuwait. ${ }^{3}$ Department of Psychiatry, University of Toronto, Toronto, Canada. ${ }^{4}$ Department of Psychiatry, Faculty of Medicine, Health Sciences Center, PO Box 24923, 13110 Safat, Kuwait.

Received: 4 March 2018 Accepted: 23 September 2018 Published online: 27 September 2018

\section{References}

1. Roca M, Gili M, Garcia-Garcia M, Salva J, Vives M, Garcia Campayo J, Comas A. Prevalence and comorbidity of common mental disorders in primary care. J Affect Disord. 2009:119:52-8,

2. Ansseau M, Dierick M, Buntinkx F, Cnockaert P, De Smedt J, Van Den Haute $M$, Vander Mijnsbrugge D. High prevalence of mental disorders in primary care. J Affect Disord. 2004;78:49-55. 
3. Sartorius N, Holt RIG, Maj M, editors. Comorbidity of mental and physical disorders. Basel: Karger AG; 2015.

4. Gili M, Comas A, García-García M, Monzon S, Antoni SB, Roca M. Comorbidity between common mental disorders and chronic somatic diseases in primary care patients. Gen Hosp Psychiatry. 2010;32:240-5.

5. Sunderji N, Kurdyak PA, Sockalingam S, Mulsant BH. Can collaborative care cure the mediocrity of usual Care for Common Mental Disorders? Can J Psychiatr. 2018;63:427-31.

6. Alkhadhari S, Alsabbrri AO, Mohammad IH, Atwan AA, Alqudaihi F, Zahid MA. Prevalence of psychiatric morbidity in the primary health clinic attendees in Kuwait. J Affect Disord. 2016;195:15-20.

7. Al-Otaibi B, Al-Weqayyan A, Taher H, Sarkhou E, Gloom A, Aseen F, et al. Depressive symptoms among Kuwaiti population attending primary healthcare settings: prevalence and influence of sociodemographic factors. Med Princ Pract. 2007:16:384-8.

8. Al-Qadhi W, Ur Rahman S, Ferwana MS, Abdulmajeed IA. Adult depression screening in Saudi primary care: prevalence, instrument and cost. BMC Psychiatry. 2014;14:190.

9. Al-Turkait FA, Ohaeri JU, El-Abassi AH, Naguy A. Relationship between symptoms of anxiety and depression in a sample of Arab college students using the Hopkins symptom checklist 25. Psychopathology 2011. 44:230-41.

10. Ohaeri JU, Awadalla AW. Characteristics of subjects with comorbidity of symptoms of generalized anxiety and major depressive disorders and the corresponding threshold and subthreshold conditions in an Arab general population sample. Med Sci Monit. 2012;18:160-73.

11. International Classification of Diseases 10th Revision. WHO. Switzerland: Geneva; 1992.

12. Diagnostic and Statistical Manual of Mental Disorders 4th Edition. American Psychiatric Association. Washington: DC; 1994.

13. Spitzer RL, Kroenke K, Williams JB. Validation and utility of a self-report version of PRIME-MD, the PHQ primary care study. Primary care evaluation of mental disorders. Patient health questionnaire. JAMA. 1999;282:1737-44.

14. Manea L, Gilbody S, McMillan D. Optimal cut-off score for diagnosing depression with the patient health questionnaire (PHQ-9): a meta-analysis. Can Med Assoc J. 2012;184:E191-6.

15. Roca M, Gili M, Garcia-Garcia M, Salva J, Vives M, Garcia Campayo J, et al. Prevalence and comorbidity of common mental disorders in primary care. J Affect Disord. 2009;119:52-8.

16. Spitzer RL, Kroenke K, Williams JB, Lowe B. A brief measure for assessing generalized anxiety disorder: the GAD-7. Arch Intern Med. 2006;166:1092-7.

17. Serrano-Blanco A, Palao DJ, Luciano JV, Pinto - Meza A, Lujan L, Fernandez A. Prevalence of mental disorders in primary care: results from the diagnosis and treatment of mental disorders in primary care study (DASMAP). Soc Psychiatry Psychiatr Epidemiol 2010; 45: 201-210.

18. Ormel J, Petukhova M, Chatterji S, Aguilar -GS, Alonso J, Angermeyer MC, al e. Disability and treatment of specific mental and physical disorders across the world. Br J Psychiatry. 2008;192:368-75.

19. Katon W, Lin EH, Kroenke K. The association of depression and anxiety with medical symptom burden in patients with chronic medical illness. Gen Hosp Psychiatry. 2007:29:147-55.

20. Härter M, Baumeister H, Reuter K, Jacobi F, Hofler M, Bengel J, et al. Increased 12-month prevalence rates of mental disorders in patients with chronic somatic diseases. Psychother Psychosom. 2007;76:354-60.

21. Scott KM, Von Korff M, Alonso J, Angermeyer MC, Bromet E, Fayyad J, et al. Mental- physical co-morbidity and its relationship with disability: results from the world mental health surveys. Psychol Med. 2009;39:33-43.

22. Lyness JM, Niculescu A, Reynolds CF, Reynolds CF $3^{\text {rd }}$, Caine ED. The relationship of medical comorbidity and depression in older, primary care patients. Psychosomatics 2006; 47: 435-439.

23. Egede E. Major depression in individuals with chronic medical disorders: prevalence, correlates and association with health resource utilization, lost productivity and functional disability. Gen Hosp Psychiatry. 2007;29:409-16.

24. Kessler RC, Chiu WT, Demler O, Merikangas RR, Walters EE. Prevalence, severity and comorbidity of 12-month DSM-IV disorders in the national comorbidity survey replication. Arch Gen Psychiatry. 2005;62:617-27.

25. Egan SJ, Wade TC, Shafran R. The transdiagnostic process of perfectionism Revisista Psicopatologia y Psicologia Clinica. 2012;17:279-94.

26. Barlow DH, Allen LB, Choate ML. Toward a unified treatment for emotiona disorders. Beh Ther. 2004;35:205-30.

\section{Ready to submit your research? Choose BMC and benefit from:}

- fast, convenient online submission

- thorough peer review by experienced researchers in your field

- rapid publication on acceptance

- support for research data, including large and complex data types

- gold Open Access which fosters wider collaboration and increased citations

- maximum visibility for your research: over $100 \mathrm{M}$ website views per year

At $\mathrm{BMC}$, research is always in progress.

Learn more biomedcentral.com/submissions 